\title{
Influence of volume working fluid and ambient temperature on cooling efficiency of loop thermosyphon
}

\author{
P. Nemec ${ }^{1, a}$, M. Malcho ${ }^{1}$, J. Jandačka $^{1}$ and J. Matušov ${ }^{1}$ \\ ${ }^{1}$ University of Žilina, Department of Power Engineering, Univerzitná 1, 01026, Žilina, Slovakia
}

\begin{abstract}
Article deal with research of device for electrical component cooling used to heat transfer working fluid phase change. Amount of heat flux transferred by thermosyphon loop depend from amount working fluid and from ambient temperature where is heat removal too. In article is described proposal construction of thermosyphon loop, comparisons of his cooling efficiency if is filled $40 \%$ and $50 \%$ volume of working fluid and condenser (ambient) temperature from 20, 30 up to $40{ }^{\circ} \mathrm{C}$ at heat load from 40 to $360 \mathrm{~W}$.
\end{abstract}

\section{Introduction}

A closed loop thermosyphon is an energy-transfer device capable of transferring heat from a heat source to a separate heat sink over a relatively long distance, without the use of active control instrumentation and any mechanically moving parts such as pumps. These devices are thus particularly suitable for cooling electronic components. The closed loop thermosyphon may be visualised as a long hollow pipe, bent and the ends joined to form a continuous loop, filled with working fluid and orientated in a vertical plane. If the one side of the loop is heated and the other side cooled, the average density of the fluid in the heated side is less than in the cooled side. An essentially hydrostatic pressure difference, as a result of the thermally induced temperature gradient between the hot and the cold sides, rives the fluid flows around the loop. The 'buoyancy' force, as it is often termed, driving the fluid is in turn counteracted by an opposing frictional force that tends to retard the flow [1]. A thermosyphon loop can transfer heat from the interior of a microelectronic system to a central location where space limitations are less stringent. The advantages that a thermosyphon system enjoys over a conventional refrigeration system include: (1) absence of moving parts leading to a more reliable system operation, (2) increased choices for selecting a working fluid compatible with microelectronics chips since it does not have to go through a refrigeration cycle, (3) reducing the decomposition rate of the working fluid as the higher temperatures at the compressor discharge in a vapour compression refrigeration system are not encountered, (4) clean operation as no oil is circulated through the system. In comparison to pool boiling systems employing vapour space condensation, a thermosyphon loop offers more flexibility in terms of providing a centralized condenser with different feed lines to individual evaporator stations. Further, with the addition of a liquid circulating pump in a thermosyphon loop, higher heat transfer coefficients associated with flow boiling systems could be realized [2].

\section{Construction of loop thermosyphon}

Main parts of the closed loop thermosyphon are:

- evaporator,

- condenser,

- pipe system to transport the working fluid,

- filling and closing valve.

On the figure 1 is shown real model of the closed loop thermosyphon. The evaporator body is made from aluminium block with parameters $116 \times 80 \times 30 \mathrm{~mm}$. In to the block are drilled two $12 \mathrm{~mm}$ diameter horizontal holes. The horizontal holes are interconnected with nine 6 $\mathrm{mm}$ diameter vertical channels to liquid transport assurance from evaporator to the condenser part of the closed loop thermosyphon. The condenser is proposed a soldering plate heat exchanger. This choice was determined by the effort to achieve a compact construction of the cooler providing the working fluid cooling in thermosyphon loop at defined temperatures of the cooling water and being able to withstand high pressures. The transport section of the closed loop thermosyphon provides the circulation of vapour and liquid phases between the evaporator and condenser of the heat pipe. The whole transport section consists of 10 $\mathrm{mm}$ copper connecting tubes. Transient glass tubes were mounted on the evaporation and condensation sides of the transport section of the heat pipe to visualize and check the working fluid flow. All connecting transient points of the whole heat pipe system are vacuum-tight. The filling

\footnotetext{
${ }^{\mathrm{a}}$ Corresponding author: patrik.nemce@fstroj.uniza.sk
} 
and closing valve is located on the top of the evaporation transport section.The electronic element fixed in a standard way to the evaporation section of the heat pipe was connected to DC power supply $120 \mathrm{~V} / 18.5 \mathrm{~A}$

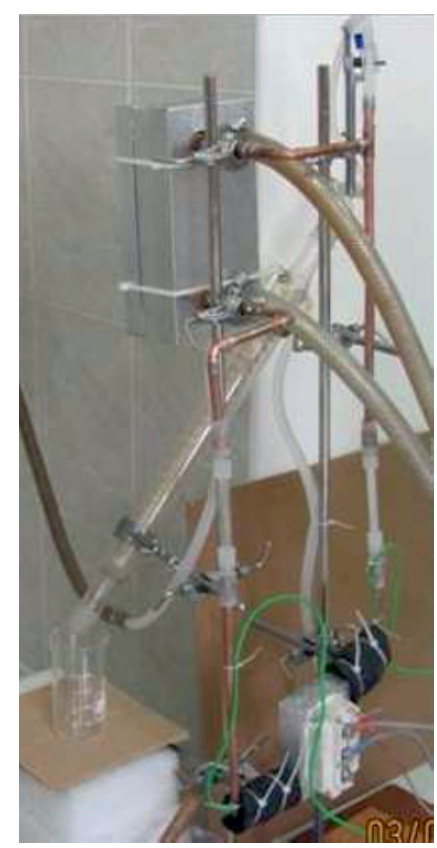

Figure 1. Loop thermosyphon

\subsection{Working fluid}

The first criterion for a design of suitable working fluid is the range or operating temperature. As there can be more working fluids within the range of suitable operating temperatures, it is, therefore, necessary to observe and compare their further thermophysical characteristics when determining the most suitable one. The main requirements for working fluid characteristics are compatibility with the heat pipe material, good temperature stability, suitable vapor pressure, large latent heat of evaporation, high thermal conductivity, low viscosity of fluid and vapor, acceptable point of freezing and solidification from the point of cooling operation [3, 4]. The choice of working fluid has also to be done on the basis of thermodynamic considerations concerning various limitations of heat transfer in heat pipes (viscose, sonic, capillary limits and limits of bubble boiling). Vapor pressure within the range of operating temperatures has to be sufficiently large to avoid high velocity of vapor which may cause instability of heat flows. The working fluid must feature high latent heat of evaporation which will enable to transfer the highest possible amount of heat with the least fluid flow provided the low pressure difference in the heat pipe is maintained. Thermal conductivity of the working fluid should be, if possible, high to minimize radial temperature gradient and decrease possibilities of film boiling on the surface walls. The resistance to the fluid flow is minimized through the choice of fluid with low values of viscosity of fluid and vapor phases [5, 6]. In compliance with the above mentioned conditions Fluorinert FC 72 was chosen as the working fluid for experimental research of the heat pipe, due to its compatibility with most metals, low boiling temperature $\left(56{ }^{\circ} \mathrm{C}\right)$ and solidification $\left(-90{ }^{\circ} \mathrm{C}\right)$ and, first of all, due to its excellent dielectric characteristics.

\section{Experiments}

How it is above mentioned, the choosing of working fluid has great influence on loop thermosyphon performance. The amount of working fluid in thermosyphon has also influence on amount transferred heat flux. This experiment deals with influence of amount working fluid on cooling efficiency. To determine the cooling efficiency of loop thermosyphon was designed measuring device consisting from measuring apparatus (resistance electronic component, power supply, thermostat, thermocouples, measuring unit, PC) shown in the figure 2 and was performed measurements with $40 \%$ a $50 \%$ amount of working fluid in loop thermosyphon. Due to possible applications of the heat pipe system serving, for heat transfer in a region up until the temperature of $40^{\circ} \mathrm{C}$, were performed measurements with the input temperature of the cooling fluid to the condenser 20,30 up to $40{ }^{\circ} \mathrm{C}$. The measurements were performed at the gradually increasing load of the electronic component fixed on loop thermosyphon evaporator with electric power from 20 to $370 \mathrm{~W}$ of DC power supply, so that the temperature of electronic component not exceed $100{ }^{\circ} \mathrm{C}$. Supplying the required heat to the evaporation section of the heat pipe, the working fluid is heated to the boiling point and starts to evaporate. Vapors of the working fluid flow along the tubes of the evaporation section of the heat pipe to its condensation section which is formed by a plate heat exchanger. Vapors of the working fluid condense on the cooling surface of the heat exchanger plates connected to the cooling circulation with a thermostat. Due to gravity the liquid phase of the working fluid flows back to the evaporator of the heat pipe. $\mathrm{Ni}-\mathrm{CrNi}$ thermocouples reading surface temperatures are connected to the evaporation and condensation sections of the closed loop thermosyphon and to the connecting surface of the electronic component and evaporator. The temperatures are recorded into a PC by means of software AMR 32 in the measurement centre.

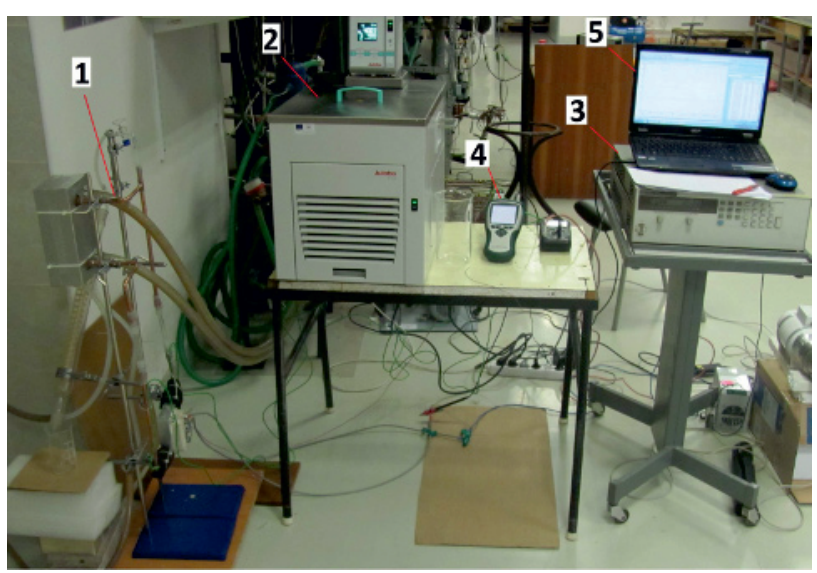

Figure 2. Measuring set-up of loop thermosyphon 


\subsection{Filing process of loop thermosyphon}

The loop thermosyphon was filled with working fluid through the filing valve in full volume. So we know total volume of loop thermosyphon. After full filling was working fluid evaporated on to required volume. Heating the evaporator section the temperature of working fluid rise and start boil $[7,8]$. Vapor flow through the pipeline to the laboratory cooler connected on filling valve when vapor condense and flow in to the measuring cylinder. In measuring cylinder is observed the volume of condensed working fluid. From difference between volume of loop thermosyphon and volume of condensed working fluid we know the working fluid volume in thermosyphon loop. During the evaporating of working fluid from loop thermosyphon occurs equilibrium state of vapor and liquid phase of working fluid without air presence.

\subsection{Flow visualization}

Heating the evaporator section of loop thermosyphon working fluid receives heat and starts evaporate. Vapor flow through the evaporator pipeline to the condenser. In the condenser on the cold surface vapor condensed, release latent heat and due pressure difference in pipeline the working fluid circulated between evaporation and condensation part of thermosyphon [9, 10]. Resulting from this the amount of working fluid and temperature of condenser are one of the factors, that affected amount heat flux transferred by loop thermosyphon. The figure 3 shows flow visualization of evaporated working fluid in the evaporator pipeline during evaporating process working fluid from loop thermosyphon. There is seen intnesive vapour phase flow in form of smal bubbles of the working fluid in the vapour pipeline of the loop thermosyphon on the right. Figure 4 shows flow visualization of working fluid during loop thermosyphon operation. There is seen vapour phase flow upwards throgh the liquid phase of working fluid in the vapour pipeline of the loop thermosyphon on the right and liquid phase flow down on the left. During operating loop thermosyphon with higher heat flux loaded in to evaporator increase his temperature and working fluid is so much intensive evaporate, that in the vapor pipeline is seen pure vapour phase and in the liquid pipeline pure liquid phase.

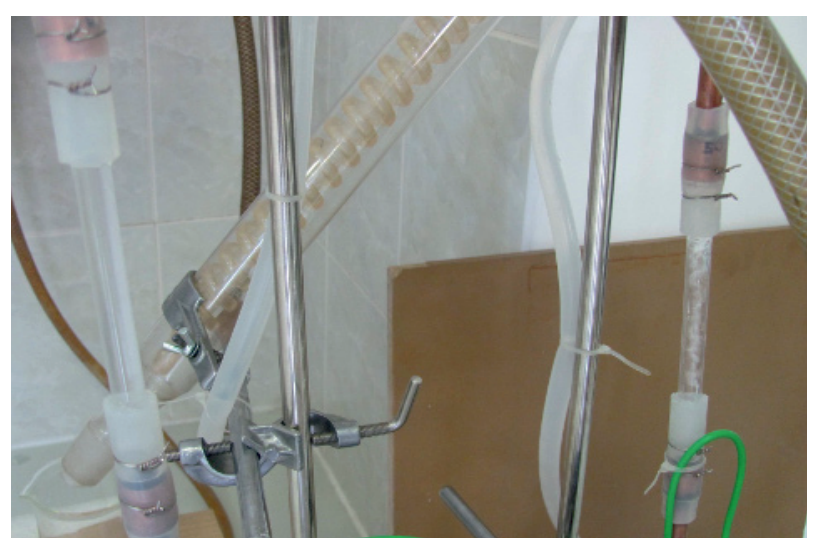

Figure 3. Working fluid evaporation

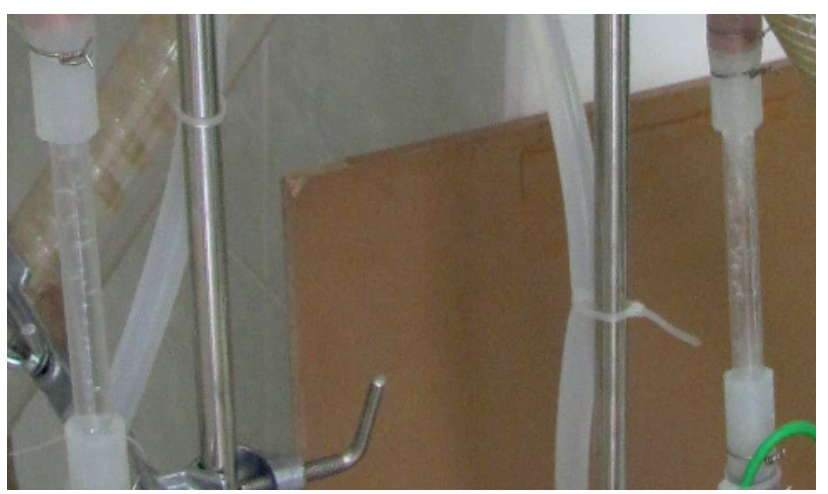

Figure 4. Working fluid flow visualization during operating of loop thermosyphon

\section{Results}

In the figure 5 and 6 are shown graphic dependences temperatures courses $t_{\text {out }}, t_{\text {in }}$ and $t_{s}$ on the input electric power in time from cooling efficiency measurement of loop thermosyphon with $50 \%$ and $40 \%$ working fluid volume at condenser temperature $40^{\circ} \mathrm{C}$. Temperature $t_{\text {out }}$ is temperature of the working fluid leaving the evaporator, temperature $t_{\text {in }}$ is temperature of the condensed working fluid entering the evaporator and temperature $t_{s}$ is temperature on the contact surface of the evaporator with the electronic component. Performance of the electronic component was gradually increased in five minute intervals by $40 \mathrm{~W}$. To measure the heat performance more than $40 \mathrm{~W}$, the time interval was extended to 31 minutes due to the recorded instability. Time intervals were not chosen randomly; they were determined from previous experiments and observation of the time interval of the stabilization of the measured closed loop thermosyphon.

In the figure 5 is seen on the start of the loop thermosyphon operation four times decrease of the temperature $t_{i n}$ in consequence intensive bubble generation and flowing of cold working fluid from plate heat exchanger to the heated evaporator. After that is seen stabilized loop thermosyphon operation.

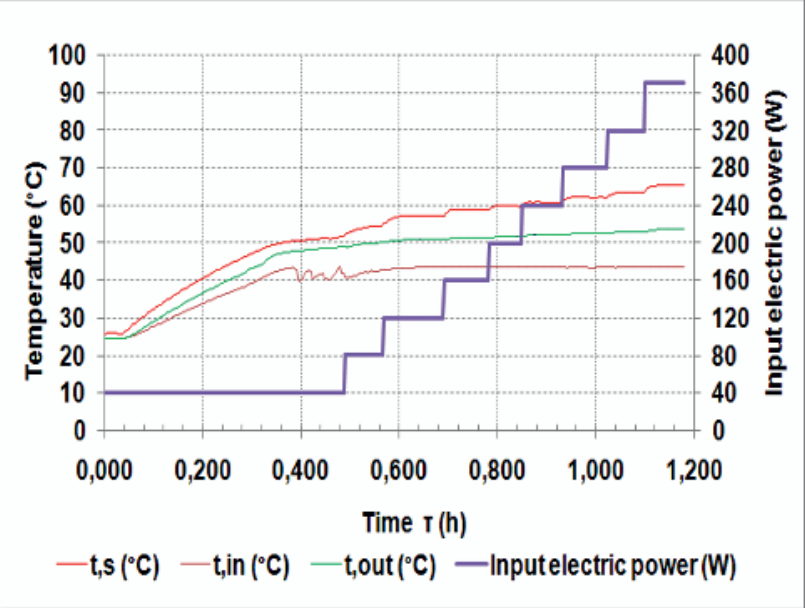

Figure 5. Dependence temperatures courses on the input electric power in time from cooling efficiency measurement of loop thermosyphon with $50 \%$ working fluid volume 


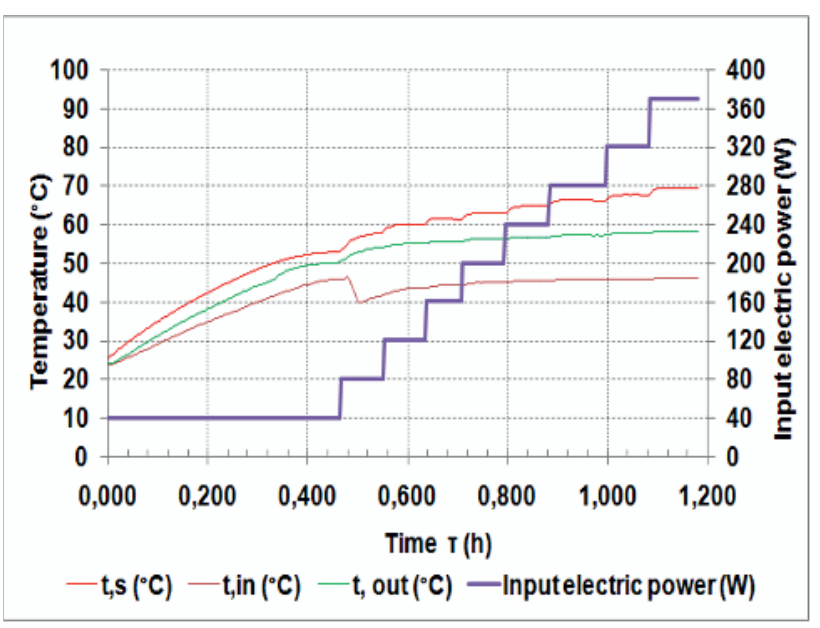

Figure 6. Dependence temperatures courses on the input electric power in time from cooling efficiency measurement of loop thermosyphon with $40 \%$ working fluid volume

In the figure 6 is seen on the start of the loop thermosyphon operation only one decrease of the temperature $t_{\text {in }}$ in consequence intensive bubble generation and flowing of cold working fluid from plate heat exchanger to the heated evaporator and after that was loop thermosyphon operation stabilized.

In the figure 7 are shown results dependence temperature course $t_{s}$ on the input electric power from cooling efficiency measurement of loop thermosyphon with $50 \%$ and $40 \%$ working fluid volume at condenser temperature 20,30 and $40^{\circ} \mathrm{C}$. Temperature courses $t_{1}, t_{2}$, and $t_{3}$ are belonging to loop thermosyphon with $50 \%$ working fluid volume. Temperature course $t_{1}$ is at condenser temperature $20{ }^{\circ} \mathrm{C}, \mathrm{t}_{2}$ is at condenser temperature $30{ }^{\circ} \mathrm{C}$, and $\mathrm{t}_{3}$ is at condenser temperature 40 ${ }^{\circ} \mathrm{C}$. Temperature courses $t_{4}, t_{5}$, and $t_{6}$ are belonging to loop thermosyphon with $40 \%$ working fluid volume. Temperature course $\mathrm{t}_{4}$ is at condenser temperature $20^{\circ} \mathrm{C}$, $\mathrm{t}_{5}$ is at condenser temperature $30^{\circ} \mathrm{C}$, and $\mathrm{t}_{6}$ is at condenser temperature $40^{\circ} \mathrm{C}$.

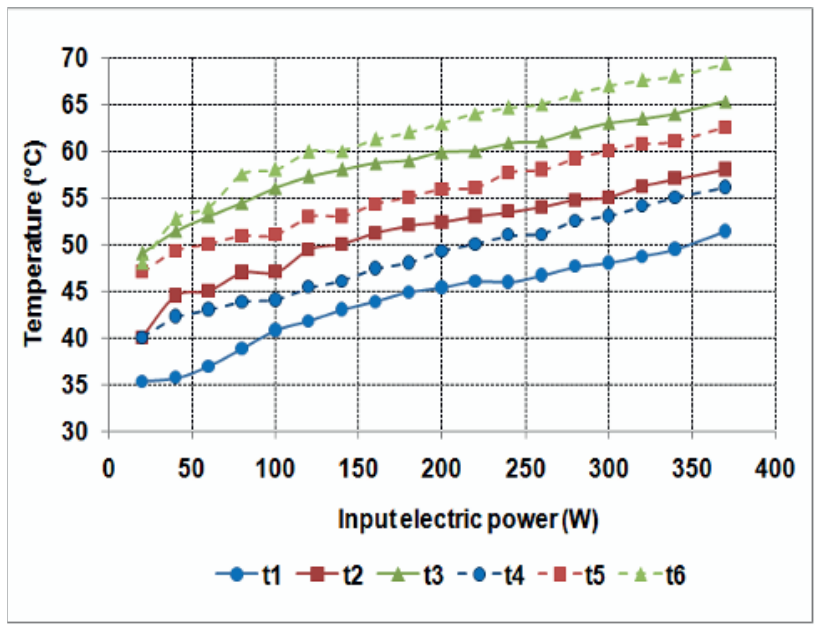

Figure 7. Dependence temperature course $t_{s}$ on the input electric power from cooling efficiency measurement of loop thermosyphon

\section{Conclusions}

The comparison of the results dependences temperatures courses $t_{s}$ on the input electric power from cooling efficiency measurement of loop thermosyphon with $50 \%$ and $40 \%$ working fluid volume at condenser temperature 20, 30 and $40^{\circ} \mathrm{C}$, leads to two conclusions. In case influence of working fluid volume on the cooling efficiency of loop thermosyphon was observed temperature difference approximately about $5{ }^{\circ} \mathrm{C}$ at every three variants of condenser temperature. In case influence of condenser temperature on the cooling efficiency of loop thermosyphon was observed temperature increase approximately about $7{ }^{\circ} \mathrm{C}$ with increased condenser temperature about $10{ }^{\circ} \mathrm{C}$ at both variants of working fluid volume. In first case was founded better operation activity with $50 \%$ volume of working fluid for this construction type of thermosyphon loop. And this result confirms claims of previous research works on this problem field. In the second case was founded significant influence of condenser temperature on cooling efficiency and also this experiment approves good cooling quality of loop thermosyphon for the applications of cooling electronic components and systems generating huge thermal flows of waste heat at high external temperatures.

\section{Acknowledgment}

This article was created within the frame of project KEGA 064ŽU-4/2012.

\section{References}

1. C. Ruppersberg, R. T. Dobson, JESA, Vol. 18, No. 3, pp. 32-40, (2007)

2. J. Hartenstine, R. Boner III, J. Montgomery, T. Semenic, ASME InterPAC, pp. 1-8, (2007)

3. A. Kapjor, J. Hužvár, P. Pilát, ERIN, pp. 57-60, (2011)

4. R. Lenhard, PCO, pp. 13, (2010).

5. P. Nemec, A. Čaja, R. Lenhard, EFM, pp. 230-235, (2009)

6. A. Čaja, P. Nemec, M. Malcho, EFM, pp. , (2008)

7. P. Nemec, A. Čaja, M.Malcho, MACM, Vol. 57, Iss. 1-2, pp. 126-136, (2013).

8. Nemec, P., Čaja, A., Malcho, M., EPJ WOC, Volume 45, Article number 01066, (2013)

9. M. Smitka, M. Malcho, P. Nemec, Z. Kolková, EPJ WOC, Volume 45, Article number 01046, (2013)

10. P. Nemec, M. Malcho, M. Smitka, J. Matušov, Communications, Vol. 14, No. 4a pp. 53-57, (2012). 